Supplement of Geosci. Model Dev., 14, 7439-7457, 2021

https://doi.org/10.5194/gmd-14-7439-2021-supplement

(C) Author(s) 2021. CC BY 4.0 License.

(c) (i)

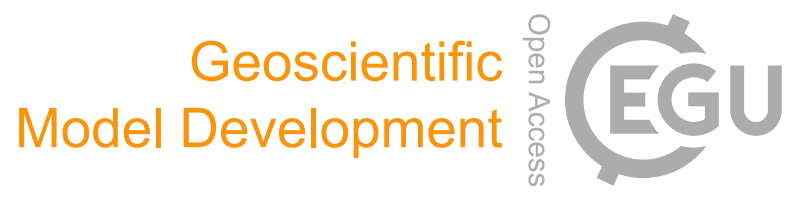

Supplement of

\title{
Concurrent calculation of radiative transfer in the atmospheric simulation in ECHAM-6.3.05p2
}

\section{Mohammad Reza Heidari et al.}

Correspondence to: Mohammad Reza Heidari (mohammad.reza.heidari@ studium.uni-hamburg.de) and Zhaoyang Song (songzhaoy@ mail.sysu.edu.cn)

The copyright of individual parts of the supplement might differ from the article licence. 
a $\mathrm{LR}_{\mathrm{CRR}}$ minus CRU (RMSE= 2.17)

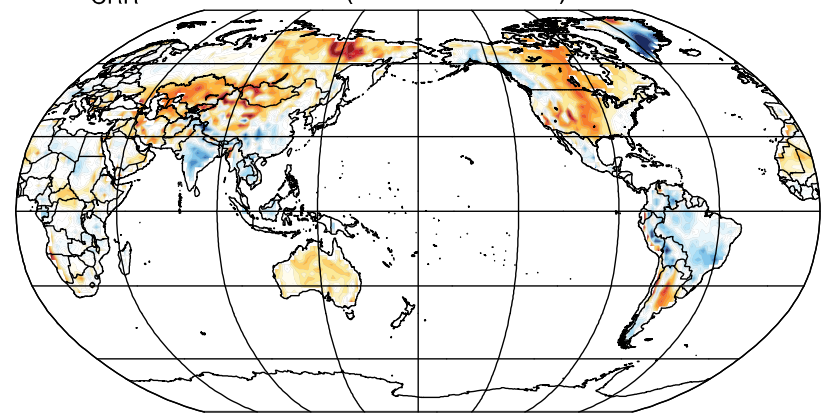

c $L R_{\text {SEQ }}$ minus CRU (RMSE = 2.29)

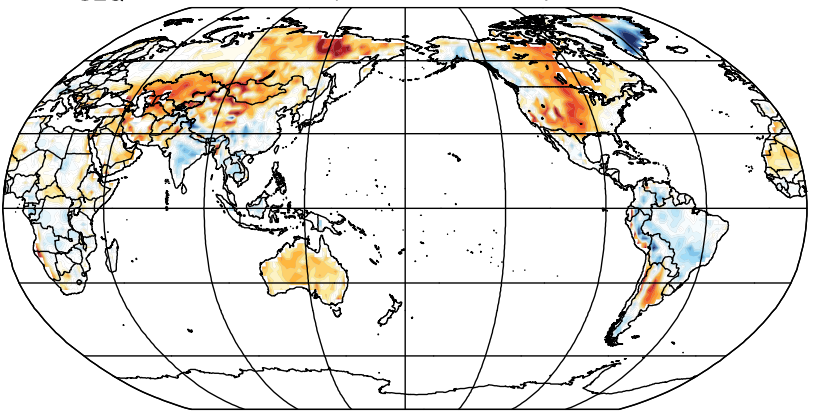

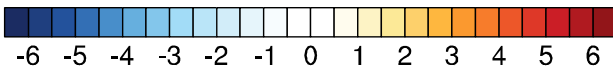

e $L R_{C R R}$ minus $L R_{\mathrm{SEQ}}$

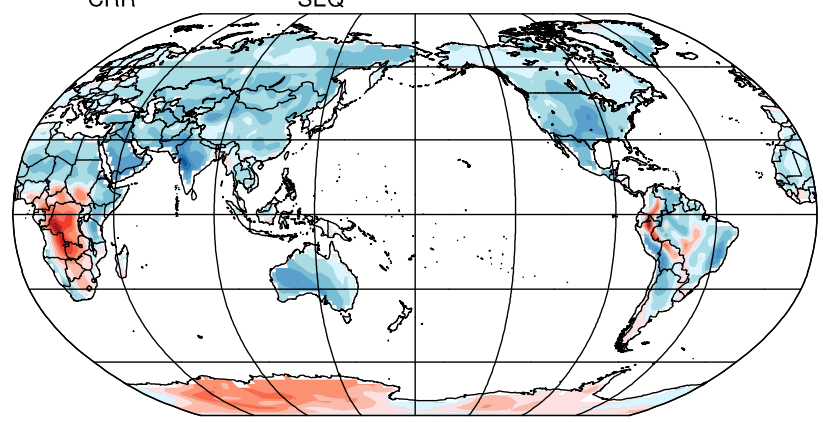

$\begin{array}{lllllllll}-1.6 & -1.2 & -0.8 & -0.4 & 0 & 0.4 & 0.8 & 1.2 & 1.6\end{array}$

K b $L_{\mathrm{CRR}}$ minus GPCP (RMSE $\left.=1.24\right)$

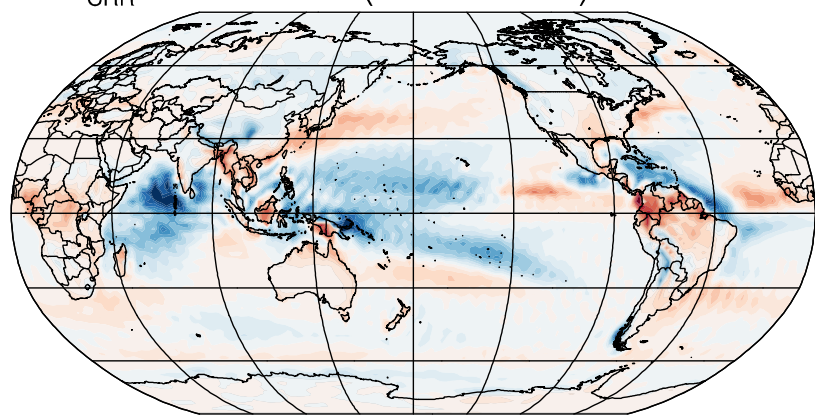

d $L_{\text {SEQ }}$ minus GPCP $(\mathrm{RMSE}=1.17)$
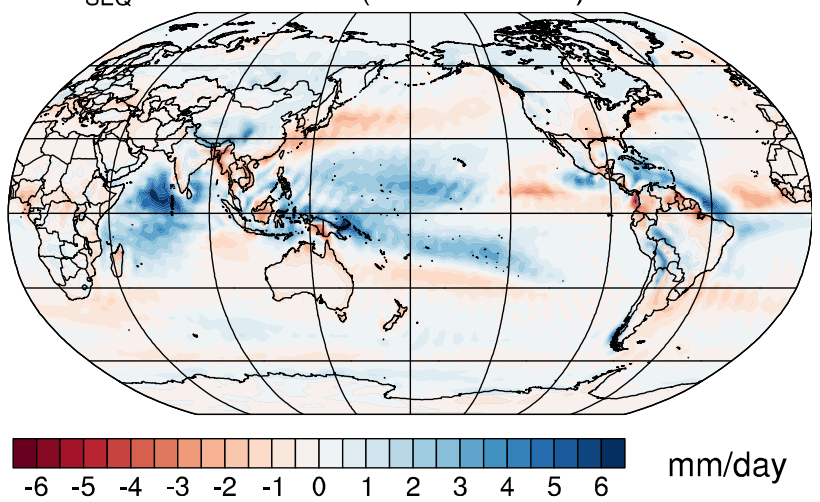

f $L R_{\mathrm{CRR}}$ minus $L R_{\mathrm{SEQ}}$

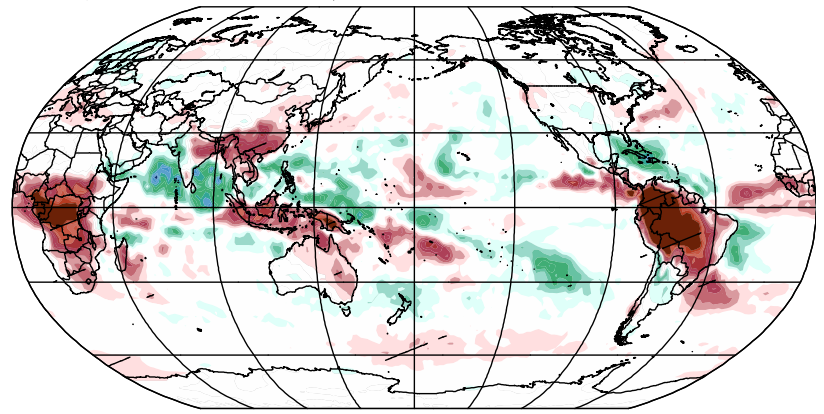

$\mathrm{mm} / \mathrm{day}$

$\begin{array}{lllllllllll}-1 & -0.8 & -0.6 & -0.4 & -0.2 & 0 & 0.2 & 0.4 & 0.6 & 0.8 & 1\end{array}$

Figure S1. Annual bias in surface-air temperature (SAT) over land $(K)$ and total precipitation (mm/day) in the (a, b) concurrent and (c, d) classical radiation experiments relative to Research Unit time series 4.01 data set (CRU TS; Harris et al., 2014) and the Global Precipitation Climatology Project data set v2.3 (GPCP; Adler et al., 2003) for the period 1980-2013, respectively. Differences in the (e) SAT over land and (f) total precipitation between the concurrent and classical radiation scheme for the period 1980-2013. Hatching indicates significance at the 95\% confidence interval using Student’s t-test. 


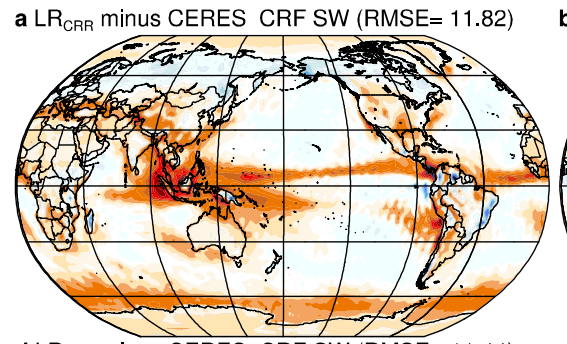

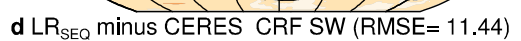
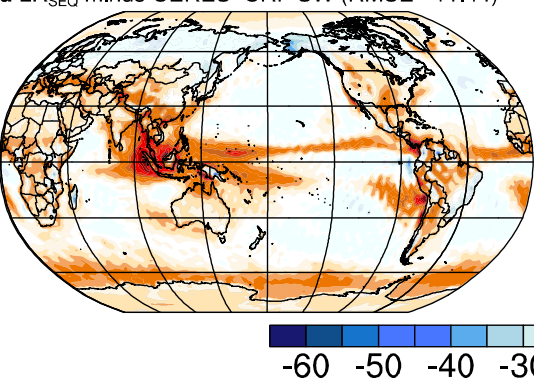

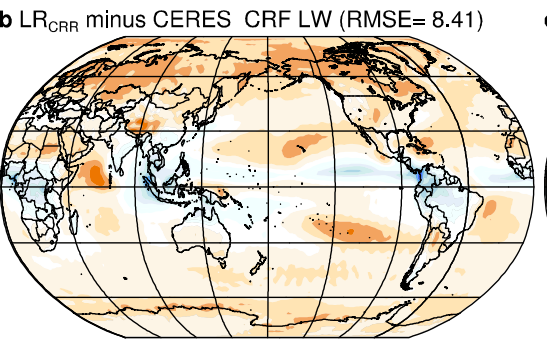

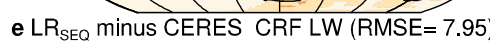

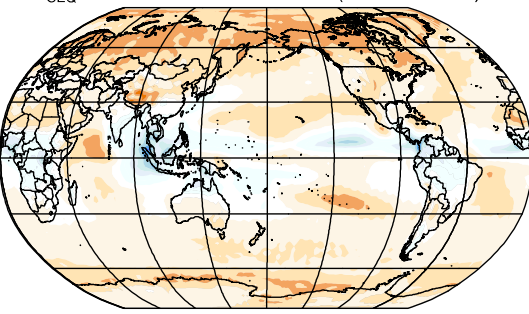

c $\mathrm{LR}_{\mathrm{CRR}}$ minus CERES TOA SW (RMSE $\left.=13.7\right)$

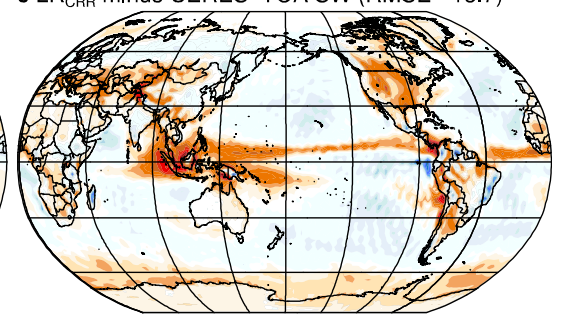

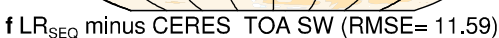

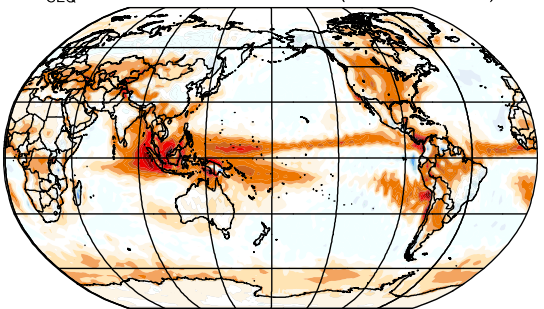

$g\left\llcorner R_{C R R}\right.$ minus $L R_{S E Q} C R F S W$

$$
\mathrm{h} L R_{\mathrm{CRR}} \text { minus } L R_{\mathrm{SEO}} \mathrm{CRF} \mathrm{LW}
$$

\section{$\begin{array}{llll}40 & 50 & 60 & \mathrm{~W} / \mathrm{m}^{2}\end{array}$}

$i \mathrm{LR}_{\mathrm{CRR}}$ minus $L R_{\mathrm{SEO}} \mathrm{TOA} S \mathrm{SW}$

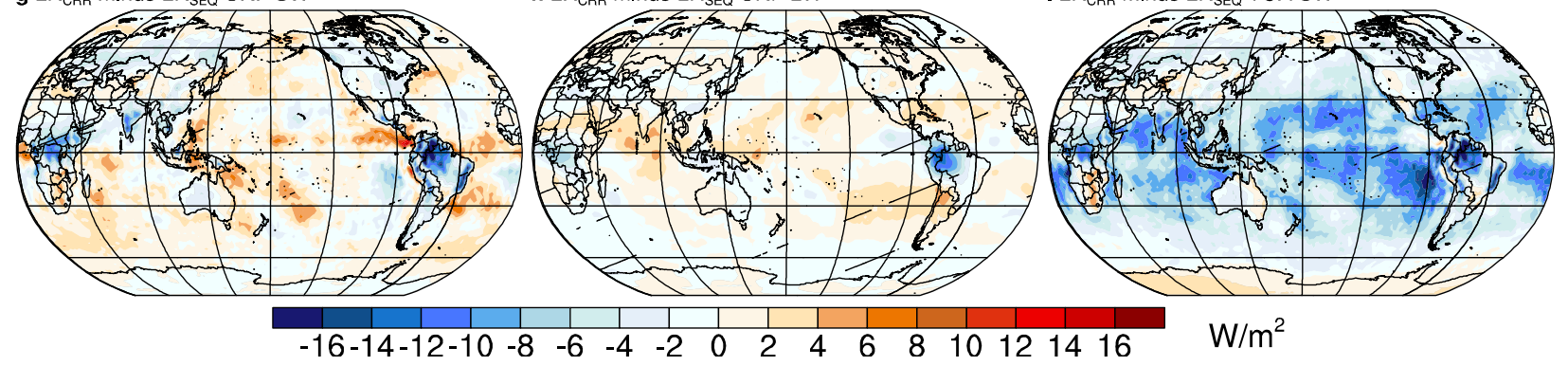

Figure S2. Annual bias in shortwave cloud radiative forcing (CRF), longwave CRF and net short wave radiation fluxes $\left(\mathrm{W} / \mathrm{m}^{2}\right)$ at the top-of-atmosphere (TOA) in the (a, b, c) concurrent and (d, e, f) classical radiation experiments relative to data from Clouds and the Earth's Radiant Energy System Energy Balanced and Filled product (CERES-EBAF) surface fluxes edition 4.0 for the period 2001-2013. Differences in the (g) shortwave CRF, (h) longwave CRF and (i) net shortwave radiation at TOA between the concurrent and classical radiation scheme for the period 2001-2013. Hatching indicates the significance at the 95\% confidence interval using Student's ttest. 

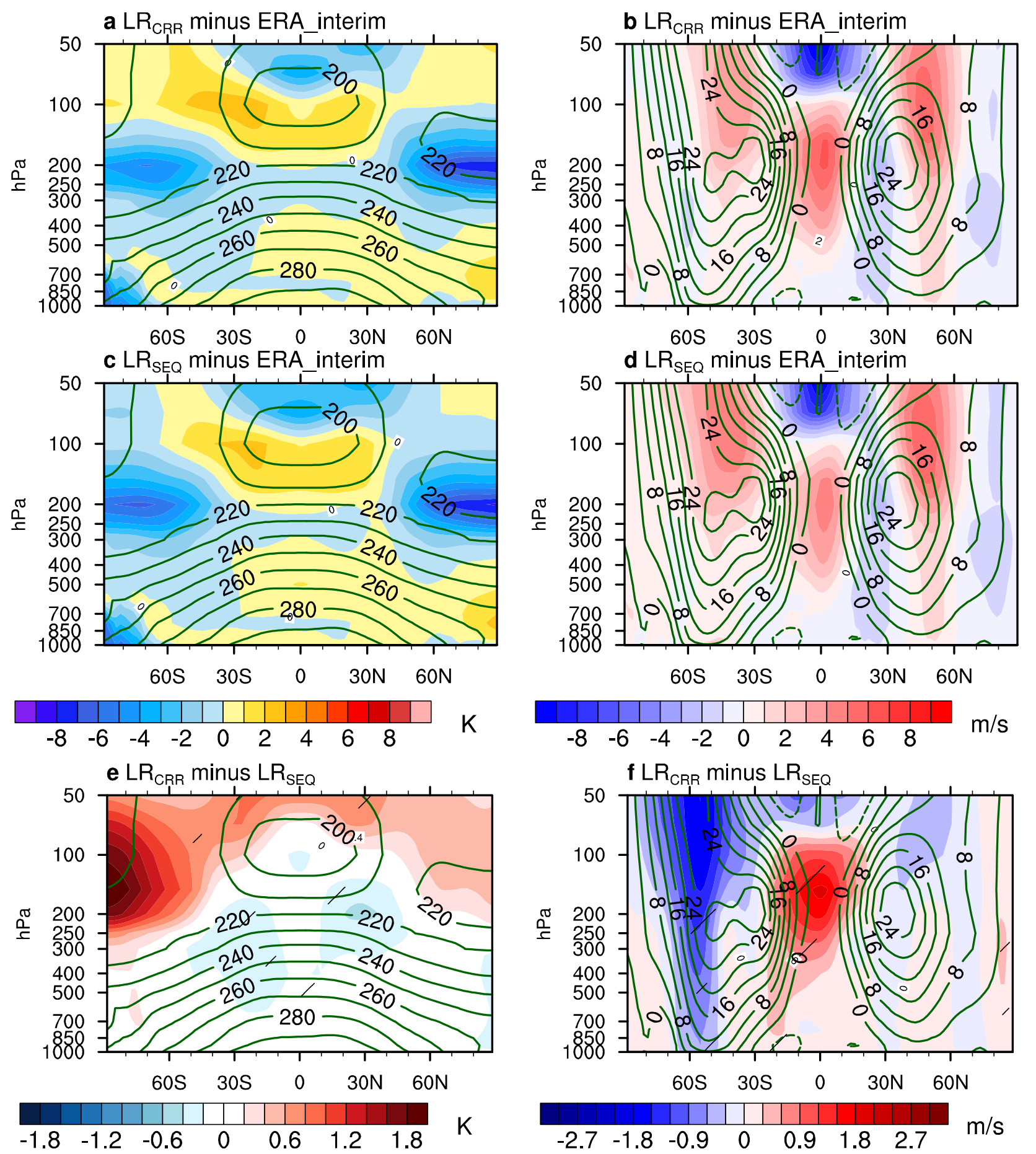

Figure S3. Mean bias in zonal-mean temperature $(K)$ and zonal wind $(\mathrm{m} / \mathrm{s})$ in the $(a, b)$ concurrent and (c, d) classical radiation experiments relative to ERA-Interim for the period 1980-2013 (shading) and the climatological mean from ERA-Interim (contours). Differences in (e) zonal-mean temperature and (f) zonal wind between the concurrent and classical radiation for the period 1980-2013. Hatching indicates the significance at the 95\% confidence interval using 
Student's t-test.

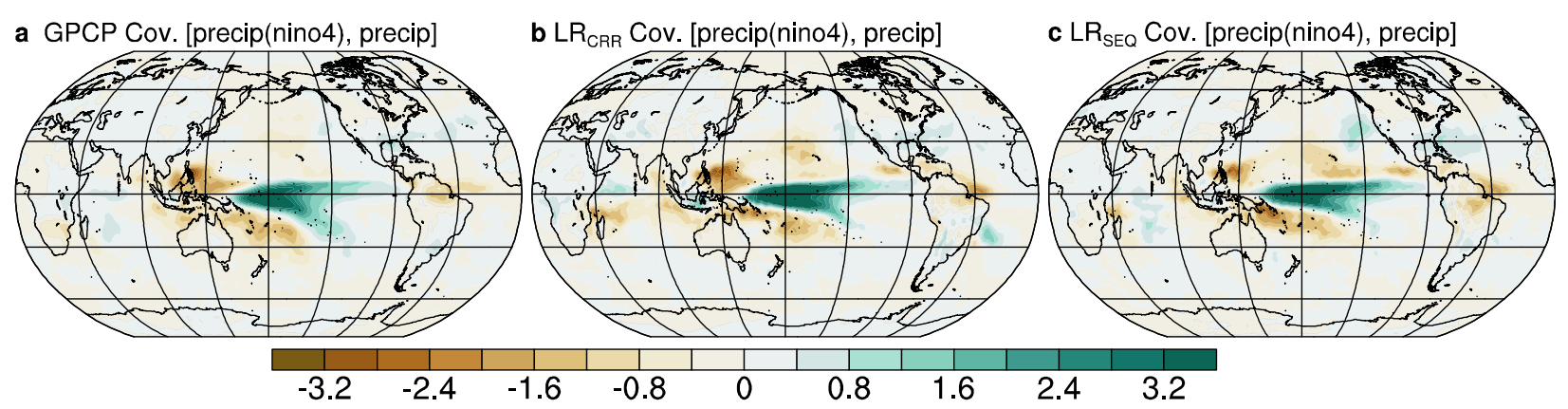

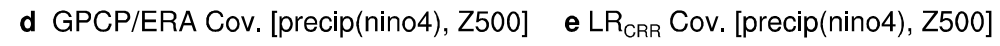
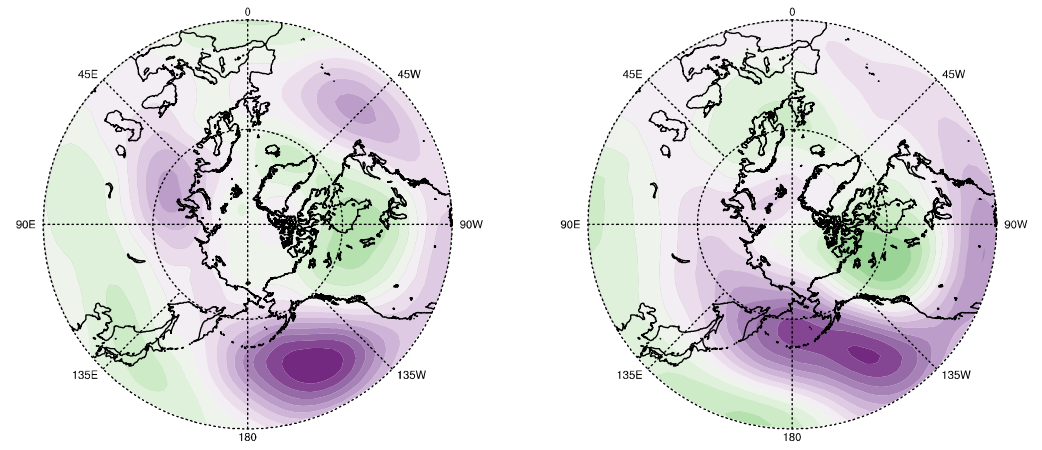

f LR $R_{\text {SEQ }}$ Cov. [precip(nino4), Z500]

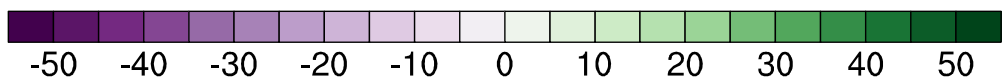

Figure S4. Covariance (mm/day·mm/day) of DJF (December-January-February) precipitation anomalies with the normalized time series of precipitation anomaly in the Niño4 region for (a) GPCP observations, (b) concurrent and (c) classical radiation experiments. Covariance (m• mm/day) of DJF 500 hPa geopotential height anomalies in the Northern Hemisphere with the normalized time series of precipitation anomaly in the Niño4 region for (d) ERA-Interim, (e) concurrent and (f) classical radiation experiments. 

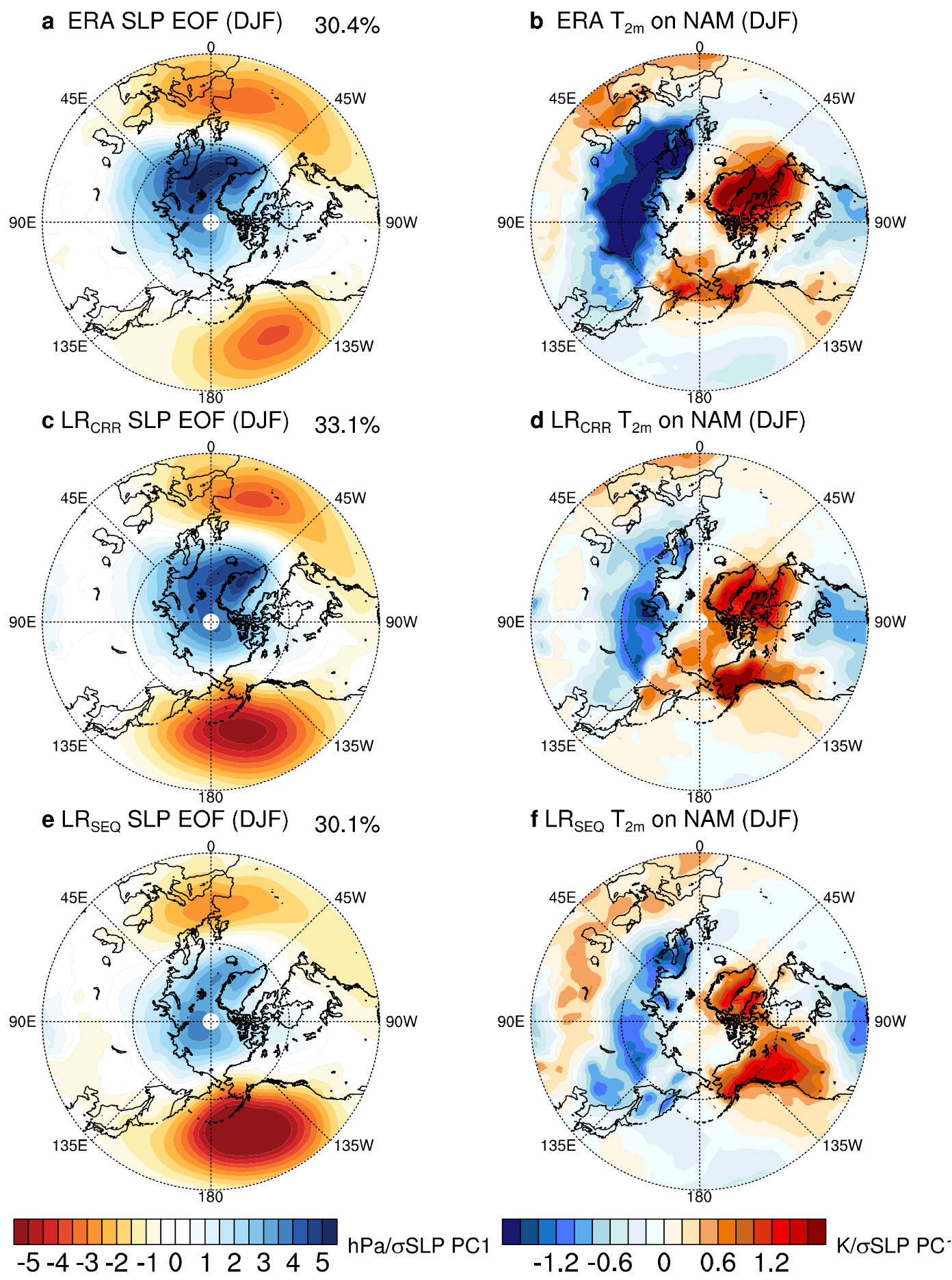

Figure S5. The leading empirical orthogonal functions (EOF) of December-January-February (DJF) sea level pressure (SLP) anomalies calculated from (a) ERA-interim, (c) concurrent and (e) classical radiation experiments for the period 1980-2013. Linear regressions of the DJF 2mair-temerpature on the NAM index (normalized PC1) from (b) ERA-interim, (d) concurrent and (f) classical radiation experiments for the period 1980-2013. 

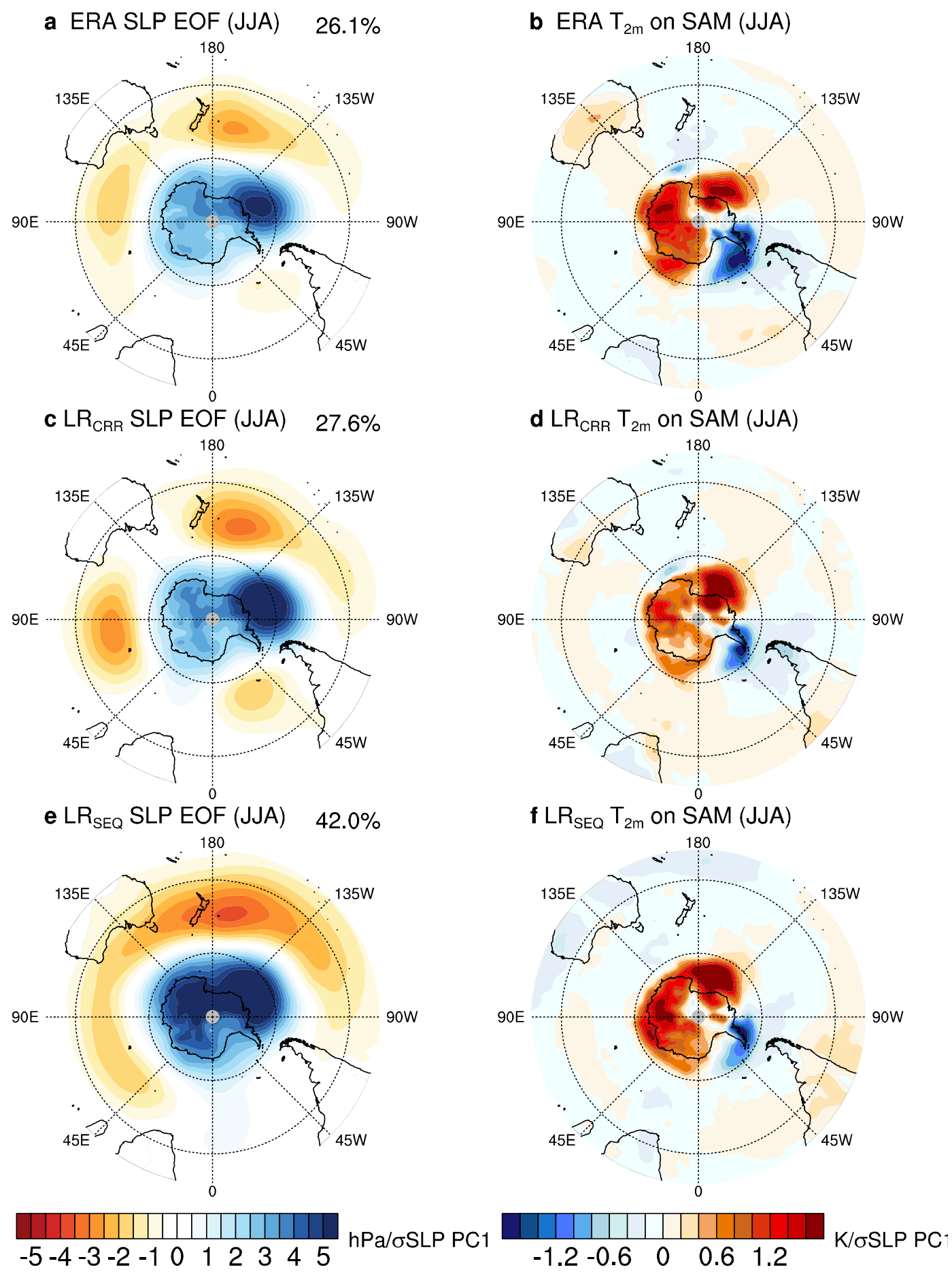

Figure S6. The leading empirical orthogonal functions (EOF) of June-July-August (JJA) sea level pressure (SLP) anomalies calculated from (a) ERA-interim, (c) concurrent and (e) classical radiation experiments for the period 1980-2013. Linear regressions of the JJA 2m-airtemerpature on the SAM index (normalized PC1) from (b) ERA-interim, (d) concurrent and (f) classical radiation experiments for the period 1980-2013. 